\title{
SISTEMA DE SUPERVISÃO E REGULAÇÃO DA EDUCAÇÃO SUPERIOR
}

\author{
CURITIBA/PR JULHO/2018
}

\author{
Tânia Aparecida Soares - Uninter - tania.so@uninter.com \\ Valdilson Aparecido Lopes - Uninter - valdilson.l@uninter.com \\ Siderly do Carmo Dahle de Almeida - Uninter - siderly.c@gmail.com
}

Tipo: Investigação Científica (IC)

Natureza: Planejamento de Pesquisa

Categoria: Estratégias e Políticas

Setor Educacional: EDUCAÇÃO SUPERIOR

\begin{abstract}
RESUMO
O processo de autorização de funcionamento de Instituição de Ensino Superior (IES), abrange faculdades, centros universitários e universidades (públicas ou privadas), nas modalidades presencial ou a distância (EAD). Este artigo tem por objetivo analisar as ações de supervisão e regulação das Instituições de Ensino Superior (IES), públicas ou privadas ofertantes da modalidade presencial ou a distância de forma a contribuir com a qualidade dos cursos oferecidos. A autorização de funcionamento dos cursos tramita dentro de um fluxo processual com diversas etapas, das quais a avaliação in loco, resulta em um relatório emitido pela comissão de técnicos designados pelo Ministério da Educação e Cultura (MEC), onde são aferidos o Conceito de Curso (CC) nos níveis de 1 a 5, sendo que valores iguais ou superiores a 3 garantem o referencial mínimo de qualidade. Pretende-se assim, verificar como a supervisão e a regulação são previstas e ainda, de que modo as mesmas ocorrem.
\end{abstract}

Palavras-chave: Regulação na Educação Superior; Educação Superior e Modalidade EAD. 


\section{INTRODUÇÃO}

Esta pesquisa desenvolveu-se a partir da observação dos autores sobre a questão do sistema de regulação da instituição de ensino superior que trabalha com a modalidade EAD, tendo por tema: sistema de supervisão e regulação dos processos de credenciamento, recredenciamento, reconhecimento e de renovação de reconhecimento das Instituições de Ensino Superior (IES) públicas ou privadas ofertantes da modalidade presencial ou a distância.

Neste contexto, a pergunta que se buscou responder com o estudo foi: "Como a experiência com os sistemas de supervisão e regulação pode contribuir face ao processo de credenciamento, recredenciamento, reconhecimento e de renovação de reconhecimento das Instituições de Ensino Superior (IES) públicas ou privadas ofertantes da modalidade presencial ou a distância? "Considerando o problema acima exposto, este artigo teve por objetivo analisar as ações de supervisão e regulação das Instituições de Ensino Superior (IES), públicas ou privadas ofertantes da modalidade presencial ou a distância de forma a contribuir com a qualidade dos cursos oferecidos.

Este trabalho justifica-se, pois, o Ministério da Educação e Cultura (MEC) só permite o início do funcionamento de instituição de educação superior mediante ato autorizativo, considerando-se os ciclos avaliativos do Sistema Nacional de Avaliação do Ensino Superior - SINAES que busca a melhoria da qualidade neste nível de educação e é importante que os docentes que atuam neste cenário conheçam suas diretrizes e prerrogativas.

Este estudo, baseado em pesquisa documental e bibliográfica, apresenta após esta introdução, uma fundamentação teórica, que contempla desde o conceito de sistema de regulação da instituição de Ensino Superior. até como deve ser organizada uma IES no que se refere ao credenciamento e recredenciamento conforme orientações da Lei de Diretrizes e Bases da Educação Nacional (LDBEN), Lei no 9.394/1996. Apresentandose, por fim, as considerações finais deste artigo.

\section{SISTEMA DE REGULAÇÃO DA INSTITUIÇÃO DE ENSINO SUPERIOR}

O Sistema Nacional de Avaliação da Educação Superior (Sinaes), instituído pela Lei no 10.861, de 14/4/2014, é um órgão que coordena e supervisiona do e com a responsabilidade de propor avaliação para atender as dinâmicas de cada Instituição de Ensino Superior (IES). A Comissão Nacional de Avaliação da Educação Superior (Conaes) tem a responsabilidade de propor mecanismos e procedimentos de avaliação do desempenho do estudante e da avaliação institucional, bem como criar diretrizes para subsidiar a elaboração de relatórios, elaborar pareceres além de encaminhar as 
recomendações às instâncias competentes.

Em 2004, o Sistema Nacional de Avaliação do Ensino Superior (SINAES) publicou a Lei no 10.861, de 14 de abril de 2004, com o objetivo de imprimir características aos processos de avaliação da Educação Superior, tendo por certo o entendimento de apontar a diferença entre os processos de avaliação e os processos de regulação. $O$ Instituto Nacional de Estudos e Pesquisas Educacionais Anísio Teixeira (Inep) tem como competência, a realização das avaliações das Instituições de Educação Superior (IES) e de seus cursos de graduação atribuídas pelo art. 8o da Lei ํo 10.861, de 14 de abril de 2004 (Lei do SINAES).

O Sistema Nacional de Avaliação do Ensino Superior (SINAES) regulamentado pela Lei no 10.861, de 14 de abril de 2004 inseriu instrumento de avaliação institucional externa de cursos de graduação (presencial e a distância) para credenciamento e recredenciamento e instrumento de avaliação de cursos de graduação (presencial e a distância) para reconhecimento, renovação de reconhecimento, com objetivo de garantir momentos de distintas etapas do processo de avaliação, integração dos espaços institucionais, caráter sistêmico da avaliação, além das informações que compreendem uma concepção global da Instituição de Ensino Superior (IES) avaliada.

A elaboração dos instrumentos de avaliação externa da Educação Superior é de responsabilidade do Instituto Nacional de Estudos e Pesquisas Educacionais Anísio Teixeira (Inep) e da legislação em vigor fixada pelo Ministério da Educação e Cultura (MEC). Fica sob a responsabilidade da Diretoria de Avaliação da Educação Superior (DAES), subordinada a Coordenação Geral de Avaliação dos Cursos de Graduação e Intuições de Ensino Superior (CGACGIES), operacionalizar, planejar conceber, coordenar a avaliação institucional.

O instrumento de avaliação institucional externa de composição do Sistema Nacional de Avaliação do Ensino Superior (SINAES), diante das diferentes dimensões da avaliação da educação superior, compreendem a avaliação institucional, em dois diferentes momentos distintos. Em um primeiro momento pelo Exame Nacional de Desempenho de Estudantes (ENADE), que visa mensurar os conhecimentos dos estudantes perante competências e habilidades e os conteúdos programáticos, conforme oriente o Instituto Nacional de Estudos e Pesquisas Educacionais Anísio Teixeira (INEP). Em um segundo momento por meio da Avaliação de Cursos de Graduação (ACG), que visa demonstrar as reais condições de oferta de ensino proposta aos estudantes, em especial as relacionadas ao corpo docente, instalações físicas, perfil do corpo docente e à organização didático-pedagógica. 
O Decreto no 9.235 de 15/12/2017 regulamenta as funções do sistema de avaliação das Instituições de Ensino Superior (IES) bem como a regulamentação dos cursos por ela ofertados. O processo de regulamentação das Instituições de Ensino Superior (IES) ocorre por meio de ações preventivas ou por meio de ações corretivas com o objetivo garantir a qualidade e regularidade dos cursos ofertados.

\section{DENOMINAÇÕES DA INSTITUIÇÕES DE ENSINO SUPERIOR (IES)}

As Instituições de Ensino Superior (IES) denominam-se públicas, quando mantidas pelo Poder Público, na forma Federal e Estadual, financiadas pelo Estado e não cobram matrícula ou mensalidade e privadas, administradas por pessoas físicas ou jurídicas de direito privado, com ou sem finalidade de lucro. As Instituições de Ensino Superior (IES) privadas sem finalidade de lucro podem ser comunitárias que incluem em sua entidade mantenedora representantes da comunidade, confessionais que atendem a determinada orientação confessional e ideológica e filantrópicas que prestam serviços à população, em caráter complementar às atividades do Estado conforme orienta o Ar. $20^{\circ}$ da Lei de Diretrizes e Bases da Educação Nacional (LDBEN|) Lei no 9.394/96.

No que se refere a organização acadêmica das Instituições de Ensino Superior (IES), nos termos do Art. 15을 do Decreto $n^{\circ} 9.235$ de 15/12/2017 Faculdade é uma categoria que recebe duas conotações. Inicialmente de uma Instituição de Ensino Superior (IES) sem autonomia para conferir títulos e diplomas, devendo registrar os mesmo em uma Universidade pública ou privada, ficando a mesma livre da função de promover a pósgraduação. Enquanto que as Universidades gozam de autonomia.

Figura 1 - Classificação acadêmico-administrativa

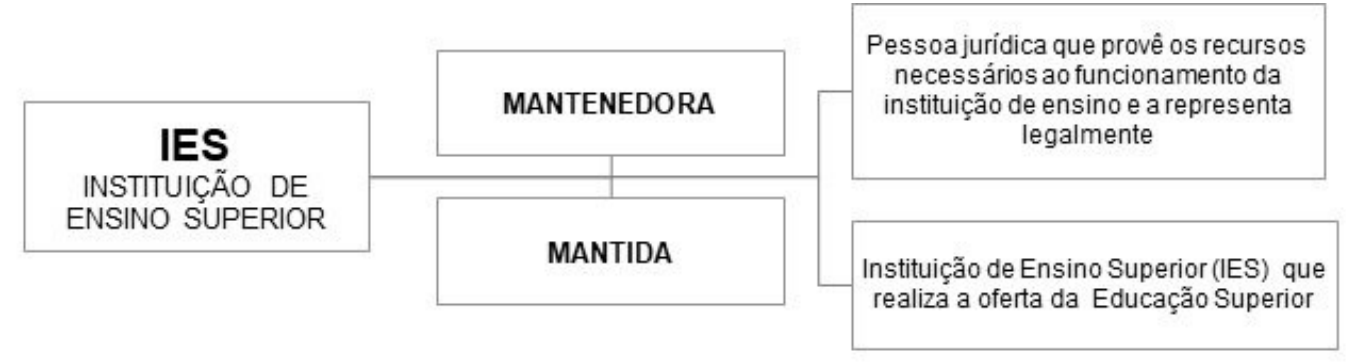

Fonte: Decreto ํㅜ 9.325 de 15/12/2017

Quanto à categoria acadêmico-administrativa, as Instituições de Ensino Superior (IES) recebem diferentes denominações. 


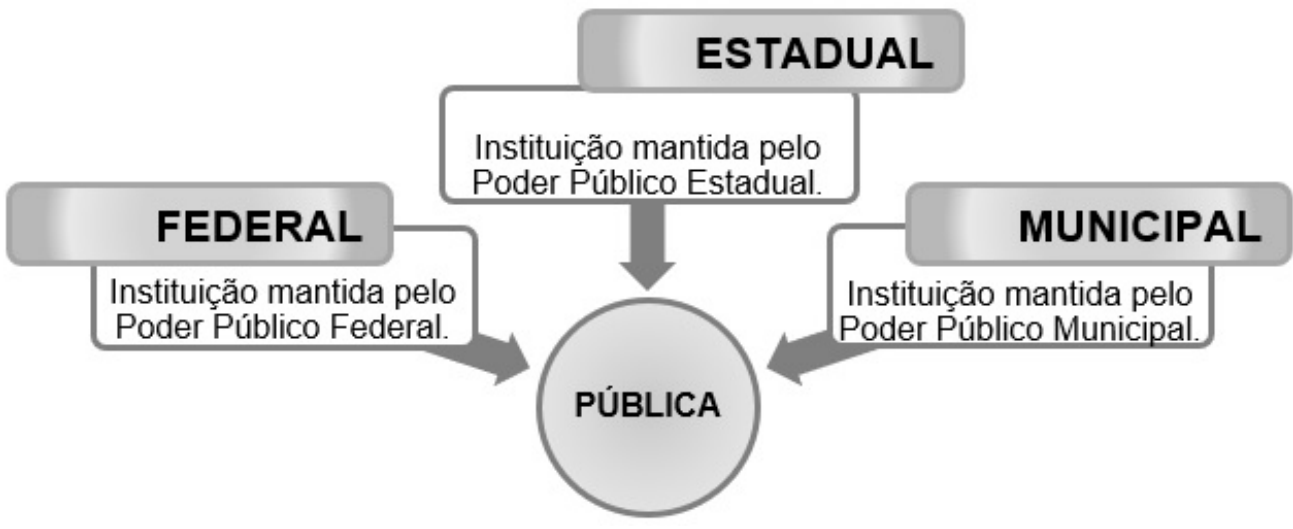

Fonte: Decreto $n^{0} 9.325$ de 15/12/2018

Assegurado por sua autonomia - no que se refere a criação de cursos e oferta de vagas, os Centros Universitários em detrimento do Art. 16 do Decreto ํo 9.235 de 15/12/2017, ficam obrigado a manter um terço do seu corpo docente com formação stricto senso, ou seja, mestres ou doutores. Quanto ao regime de trabalho do corpo docente - ainda no Art. 16 do mesmo decreto, $1 / 5$ da integralidade do corpo docente deverá estar contratado em regime de trabalho integral. Devido sua configuração - pluricurricular atende várias áreas do conhecimento e assemelha-se à Universidade no que se refere a sua estrutura, contudo não se encontra definido na Lei de Diretrizes e Bases (LDB) Lei no 9.394/96 os requisitos de pesquisa institucionalizada.

\section{CREDENCIAMENTO E RECREDENCIAMENTO DE IES}

Quanto a organização, o credenciamento de uma instituição de ensino superior conforme orientações da Lei de Diretrizes e Bases da Educação Nacional (LDBEN), Lei no 9.394/1996 nos termos do art. 46, é compreendida como uma modalidade de ato autorizativo de funcionamento público ou privado. Conforme a escolha da organização acadêmica, as instituições são credenciadas como as Faculdades/ Centros Universitário/Universidade.

Atendendo as orientações da legislação vigente e decorrente do Ministério da Educação e Cultura (MEC), uma instituição de ensino superior é credenciada inicialmente como Faculdade. Posteriormente, atendendo as prerrogativas de autonomia e o padrão satisfatório de qualidade identificados no decorrer do seu funcionamento, uma Faculdade poderá solicitar sua transformação de Faculdade para Centro Universitário e de Centro Universitário para Universidade.

Figura 2 - Credenciamento 
- Art. 15 do Decreto ${ }^{\circ}$ 9.235 de $15 / 12 / 2017$

FACULDADE
CENTRO

UNIVERSITÁRIO

- Art. 16 do Decreto $\mathrm{n}^{\circ} 9.235 \mathrm{de}$ $15 / 12 / 2017$
- Art. 17 do

Decreto $\mathrm{n}^{0} 9.235$

de $15 / 12 / 2017$

UNIVERSIDADE

Fonte: Decreto ํㅜ 9.325 de 15/12/2018

Inicialmente - ao ser credenciada - uma Faculdade recebe do Ministério da Educação e Cultua (MEC) e conforme determina o ciclo avaliativo do Sistema Nacional de Avaliação da Educação Superior (Sinaes) regulamentado pela Lei $\mathrm{n}^{0}$ 10.861, de 14 de abril de 2004 em seu art. 4ํㅜ o prazo de funcionamento de 5 (cinco anos), exceto as Universidades devido a sua autonomia recebe o prazo de 10 (dez) anos. Para que uma instituição de ensino superior oferta formação na modalidade a distância (EAD), necessariamente - conforme o disposto no Art. 10 (caput e $\S 7^{\circ}$ ) do Decreto $\mathrm{n}^{\circ}$ 5.622/2005 - previamente deverá estar credenciada para oferta de educação superior na modalidade presencial no sistema federal de ensino.

Quanto a situação legal das instituições de ensino superior, a oferta de curso superior, em instituições de educação superior devem obrigatoriamente deve estar condicionada ao seu credenciamento. No caso das instituições privadas, cabe ao Ministério da Educação e Cultura (MEC) expedir este ato, que atendendo a cada ciclo avaliativo, deverá ser renovado.

Quanto a formação - ao ser credenciada - uma faculdade recebe autorização para a oferta das seguintes modalidades de ensino: presencial e a distância (EAD). Na modalidade educacional presencial, pressupõe presença física do aluno nas atividades didáticas e avaliações. Enquanto que modalidade educacional a distância (EAD), a mediação nos processos didático-pedagógico transcorre por meio da Tecnologia de Informação e Comunicação (TIC), com professores e alunos no desenvolvimento das atividades educativas em tempos ou lugares deferentes.

No que se refere ao processo de recredenciamento das Instituições de Ensino Superior (IES), conforme exigência legal do Ministério da Educação e Cultura (MEC), consta no Art. 25으 até o Art. 28ำ do Decreto ํ 9.235 de 15/12/2017 que a IES deve protocolar pedido de recredenciamento junto à secretaria de regulação e supervisão da educação superior do ministério da educação, observado o calendário definido pelo ministério da 
educação e dentro do prazo fixado no ato autorizativo vigente.

E ainda que as faculdades com Conceito Institucional $(\mathrm{Cl})$ máximo nas duas últimas avaliações, não tenham sido penalizadas em decorrência de processo administrativo de supervisão nos últimos dois anos, contados da data de publicação do ato que a penalizou, poderão receber a atribuição de registrar seus próprios diplomas de graduação, nos termos de seu ato de recredenciamento, conforme regulamento a ser editado pelo ministério da educação.

Quadro 1 - Prazo de validade dos Atos Autorizativos Institucionais

\begin{tabular}{|c|c|c|c|c|}
\hline \multirow{4}{*}{$\begin{array}{l}\text { ORGANIZAÇÃO } \\
\text { ACADÊMICA }\end{array}$} & \multicolumn{4}{|c|}{ PRAZOS PARA CREDENCIAMENTO E RECREDENCIAMENTO } \\
\hline & \multirow{2}{*}{\multicolumn{2}{|c|}{$\begin{array}{l}\text { CREDENCIAMENTO E } 19 \\
\text { RECREDENCIAMENTO }\end{array}$}} & \multirow{2}{*}{\multicolumn{2}{|c|}{$\begin{array}{c}\text { A PARTIR DO } 2{ }^{\circ} \\
\text { RECREDENCIAMENTO }\end{array}$}} \\
\hline & & & & \\
\hline & $\begin{array}{c}\text { CONDICIONALIDAD } \\
\text { E }\end{array}$ & PRAZO & CONDICIONALIDADE & PRAZO \\
\hline \multirow{3}{*}{$\begin{array}{l}\text { FACULDADE E } \\
\text { CENTRO } \\
\text { UNIVERSITÁRIO }\end{array}$} & $\mathrm{Cl} 3$ & 3 anos & IGC 3 & 3 anos \\
\hline & $\mathrm{Cl} 4$ & 4 anos & IGC 4 & 4 anos \\
\hline & $\mathrm{Cl} 5$ & 5 anos & IGC 5 & 5 anos \\
\hline \multirow[t]{3}{*}{ UNIVERSIDADE } & $\mathrm{Cl} 3$ & 5 anos & IGC 3 & 5 anos \\
\hline & $\mathrm{Cl} 4$ & 8 anos & IGC 4 & 8 anos \\
\hline & $\mathrm{Cl} 5$ & 10 anos & IGC 5 & 10 anos \\
\hline
\end{tabular}

Fonte: Brasil, Decreto no. 9.235 de 15/12/217

No sentido de atender as particularidades de cada caso, o Decreto no 9.235 de $15 / 12 / 2017$, fixa diferenciados prazos de validade referente os atos de credenciamento e recredenciamento, conforme a organização acadêmica e os indicadores de qualidade da Instituição de Ensino Superior (IES).

\section{Autorização de Funcionamento de Curso Superior}

O processo de autorização de funcionamento da (IES, abrange: Faculdades, Centros Universitários e Universidades (públicas ou privadas), nas modalidades presencial ou a distância (EAD). A autorização de funcionamento dos cursos tramita dentro de um fluxo processual com diversas etapas, das quais a avaliação in loco, resulta em um relatório emitido pela comissão de técnicos designados pelo Ministério da Educação e Cultura (MEC), onde são aferidos o Conceito de Curso (CC) nos níveis de 1 a 5 , sendo que valores iguais ou superiores a 3 garantem o referencial mínimo de qualidade. 
O Sistema Nacional de Avaliação da Educação Superior (Sinaes), prevê no decorrer do processo de autorização de funcionamento a avaliação de três dimensões previstas no Projeto Pedagógico do Curso (PPC): Organização Didático-Pedagógica, Corpo Docente e Tutorial e Infraestrutura. Cabe ressaltar, que os conceitos obtidos ao término de cada visita in loco não resultam no deferimento do ato autorizativo, contudo, subsidiam as secretarias competentes do Ministério da Educação e Cultura (MEC) em suas decisões regulatórias.

Em um processo de autorização de funcionamento para a oferta de um curso superior graduação (presencial ou EAD) em uma Faculdade, somente poderão iniciar oferta de curso superior, após a emissão de Portaria Ministerial publicada pelo Ministério da Educação e Cultura (MEC). Enquanto que os Centro Universitários e as Universidades por gozarem de autonomia, independem de autorização do Ministério da Educação e Cultura (MEC) para o funcionamento de curso superior. Contudo, essas instituições de ensino superior devem comunicar à Secretaria competente os cursos abertos para fins de supervisão, avaliação e posterior reconhecimento, conforme disposto no art. 5o do Decreto ํㅜ 9.235 de 15/12/2017.

Os cursos superiores de educação são abertos a candidatos que concluíram o Ensino Médio ou equivalente e tenham sido classificados em processo seletivo (vestibular), conferindo os graus de Licenciatura, Bacharelado ou Tecnologia. Conforme consta no Art. 44, inc. III da Lei de Diretrizes e Bases - Lei 9394/96.

\section{?6 RECONHECIMENTO E RENOVAÇÃO DE RECONHECIMENTO}

?O processo de reconhecimento e de renovação de reconhecimento que atende os cursos superiores na esfera nacional orientados pelas diretrizes do Ministério da Educação e Cultura (MEC), abrange instituições (faculdades, centros universitários e universidades) públicas ou privadas se vale do instrumento de avaliação de cursos de graduação na modalidade presencial e a distância (EAD) para a aferição as três dimensões. Assim, conforme indicados na Nota Técnica oㅜ 16/2017, os pesos para os atos de autorização, reconhecimento e renovação de reconhecimento passam a ser:

O ato de autorização de funcionamento dos cursos superiores - dada a sua natureza -, possuem relevância nas dimensões: DIMENSÃO I - Organização Didático-pedagógica e DIMENSÃO III - Infraestrutura, que deverão estar consolidadas, elaboradas e construídas respectivamente.

Enquanto que a dimensão II (Corpo Docente) apresenta caráter de existência potencial, fato decorrente da exigibilidade de contratação efetiva do corpo docente ocorrer após a 
publicação da portaria do ato autorizativo em questão. $O$ ato de reconhecimento e de renovação de reconhecimento, pontua considerada relevância nas dimensões: DIMENSÃO I - Organização Didático-pedagógica e a DIMENSÃO III - Infraestrutura.

Contudo a dimensão 2 recebe destaque de acentuada relevância, observada as condições em que o curso se encontra em funcionamento fato este da exigibilidade efetiva de contratação do corpo docente. Assim, os elementos que serão avaliados nesta dimensão 2, são observados como operacionalizadores da concepção do curso à priori autorizado, além de serem considerados como protagonistas das atividades de ensino, pesquisa e extensão.

Conforme o disposto do Decreto 5.773, 09/05/2006, Art. 35, as Instituições de Ensino Superior (IES), deverão protocolar junto ao Ministério da Educação e Cultura (MEC), a solicitação de Reconhecimento de seus cursos, no período entre metade do prazo previsto para a integralização da carga horária total da matriz curricular e setenta e cinco por cento desse prazo. Na redação do mesmo decreto, consta que as IES devem solicitar o reconhecimento dos cursos por ela ofertados após o cumprimento de $50 \%$ (cinquenta por cento) do cumprimento da carga horária prevista na matriz curricular do curso (e antes de completar 75\%), assegurando a condição necessária para a validação de diplomas.

\section{CONSIDERAÇÕES FINAIS}

De acordo com a legislação vigente, as Instituições de Ensino Superior (IES) são submetidas periodicamente a um processo avaliativo para obter o reconhecimento necessário dada as condições de oferta cabe a Instituição de Ensino Superior (IES), a cada ciclo avaliativo, deve solicitar junto ao sistema e-MEC o pedido de renovação de reconhecimento dos cursos por ela ofertados, conforme estabelecido pelo Decreto oㅜ 9.325/20017, fixando assim, o tempo de duração de um reconhecimento.

Atendendo ao ciclo avaliativo, a Instituição de Ensino Superior (IES) protocola junto ao e$\mathrm{MEC}$, a solicitação de renovação do seu ato de autorização conforme prevê o Art. 46으 da Lei de Diretrizes e Bases (LDB). A importância dos atos de autorização, possibilitam por meio dos resultados avaliar a qualidade das Instituições de Ensino Superior (IES) e dos cursos por ela ofertados, colocando em destaque, como necessário, as inovações institucionais e governamentais da área educacional.

A Instituições de Ensino Superior (IES) que protocolar junto ao e-MEC a solicitação de reconhecimento de seus cursos no prazo previsto e não receber visita in loco até a data de conclusão da primeira turma, poderá se considerar reconhecida dada a exclusividade 
apenas para fins de expedição e registros de diploma.

\section{REFERÊNCIAS}

ASSOCIAÇÃO BRASILEIRA DE MANTENEDORAS DO ENSINO SUPERIOR. Portaria SERES no 347, de 24 de abril de 2017. Disponível em: http://abmes.org.br/legislacoes/detalhe/2095 Acesso em: 07 maio 2018.

BRASIL. Decreto no 9.235, de 15 de dezembro de 2017. Disponível em: http://www.planalto.gov.br/ccivil_03/_Ato2015-2018/2017/Decreto/D9235.htm. Acesso em: 07 maio 2018.

BRASIL. Decreto $\mathbf{n}^{\circ}$ 5.773, de 09 de maio de 2006. Disponível em: http://portal.mec.gov.br/seed/arquivos/pdf/legislacao/decreton57731.pdf Acesso em: 07 maio 2018.

BRASIL. Decreto no 5.622, de 19 de dezembro de 2005. Disponível em: https://www.planalto.gov.br/ccivil_03/_Ato2004-2006/2005/Decreto/D5622.htm Acesso em: 07 maio 2018.

BRASIL. Lei no 9.394, de 20 de dezembro de 1996. Estabelece as diretrizes e bases da educação nacional. Disponível em: http://www.planalto.gov.br/ccivil_03/leis/l9394.htm>. Acesso em: 07 maio 2018.

BRASIL. Lei no 10.861, de 14 de abril de 2004 . Disponível em:http://portal.mec.gov.br/arquivos/pdf/leisinaes.pdf Acesso em: 07 maio 2018.

BRASIL. Lei no 11.892, de 29 de dezembro de 2008. Disponível em: http://www.camara.gov.br/sileg/integras/724044.pdf Acesso em: 07 maio 2018. 